2. Williams G, Pickup JC, Bowcock S, Cook E, Keen H (1983) Subcutaneous aprotinin causes local hyperaemia: A possible mechanism by which aprotinin improves control in some diabetic patients. Diabetologia 24:91-94

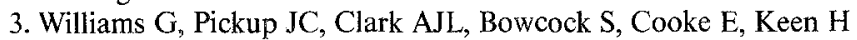
(1983) Changes in blood flow close to subcutaneous insulin injection sites in stable and brittle diabetics. Diabetes 32: 466-473

4. Williams G, Pickup JC, Collins AGC, Keen H (1984) Prostaglandin $\mathrm{El}$ accelerates subcutaneous insulin absorption in insulin-dependent diabetic patients. Diabetic Medicine 1:109-112

5. Williams G (1985) Blood flow at insulin injection sites. In: Pickup JC (ed) Brittle diabetes. Blackwell, Oxford, pp 132-153

Dr. G. Williams

Endocrine Unit

Hammersmith Hospital

London W12 OHS

UK

\section{Dr. J.Pickup}

Department of Chemical Pathology

Guy's Hospital Medical School

London SE1 9RT

UK

\section{Diet and Type 1 (insulin-dependent) diabetes}

Dear Professor Berger,

I read with interest the article by McCulloch et al. [1] examining "Imaginative and Practical Teaching Methods" as influences on dietary compliance and metabolic control in Type 1 (insulin-dependent) adults. It is widely accepted that the gulf between the theory and practice of dietary treatment in diabetes is large, and measures to reduce this gulf are to the welcomed.

It is important, however, not to take the results of a single study of groups of 12 patients chosen for their poor control to suggest that modern diabetic diets reducing total fat and increasing fibre (especially gel fibre) are not of value. The fairly broad consensus for the treatment of diabetic patients [2] is based on a very wide range of published papers and studies, and is not aimed solely at the improvement in blood glucose levels. The authors talk of improving metabolic control in their study patients, but report only glycosylated haemoglobin levels and not cholesterol or other metabolic parameters.

Specific comments need to be made about the study itself:

1. The compliance of patients taking part in studies of between 15 and 19 months duration may vary, and this may be evident from the gly- cosylated haemoglobin results for the control group A in the second part of their 15-month study.

2. To study the experimental group for 4 months longer than the two control groups is likely to bias results.

3. The drop-out of two patients from the conventional diet group B may distort results by the inclusion of more compliant patients. This might be a reason why the group B patients, reduced to 10 , had glycosylated haemoglobins $1 \%$ lower than the other two groups. While not statistically different, this may be sufficient to affect later results.

4. In respect of glycosylated haemoglobin values, those given in Figure 3 seem to have standard error bars inappropriately small for the values given in Table 1 and given in the text.

The authors may have achieved some improvement in diabetic control in their patients by their teaching programme, and I would agree that consistency and timing of carbohydrate intake is very important. Their study does not show that a low fat, high fibre, high complex carbohydrate diet does not improve diabetic control.

Few of their high fibre patients were shown to increase gel fibre sources (Table 3 ). Only moderate increases in total fibre intake were seen, to a level actually matched by the Group B patients, who were not given the dietary advice in the second intervention period. One may therefore conclude that the teaching in the second intervention period was unsuccessful, rather than conclude that the dietary recommendations of the British Diabetic Association and of others are not valid.

Yours sincerely,

J. Reckless

Chairman, Nutrition Sub-Committee, British Diabetic Association

\section{References}

1. McCulloch DK, Mitchell RD, Ambler J, Tattersall RB (1985) A prospective comparison of "conventional" and high carbohydrate/ high fibre/low fat diets in adults with established Type I (insulindependent) diabetes. Diabetologia 28:208-212

2. Statement by the British Diabetic Association (1982) Dietary recommendations for diabetes for the 1980s. Hum Nutr Appl Nutr 36a: $378-394$

\section{Dr. John Reckless}

Royal United Hospital

Combe Park

Bath BA1 3NG

UK

\title{
Erratum
}

Diabetologia, Volume 29, Number 1, January 1986, p. 22

Article by W. Burger et al.: Prevalence and development of retinopathy in children and adolescents with Type 1 (insulin-dependent) diabetes mellitus. A longitudinal study

Please note that in the fourth sentence in the last paragraph of the above-mentioned paper, the word proliferative should be replaced by pre-proliferative. This sentence should read:

'Only 5 years later, retinal changes reach the pre-proliferative state of no return.'

The publisher regrets that this correction was not carried out before going to press. 